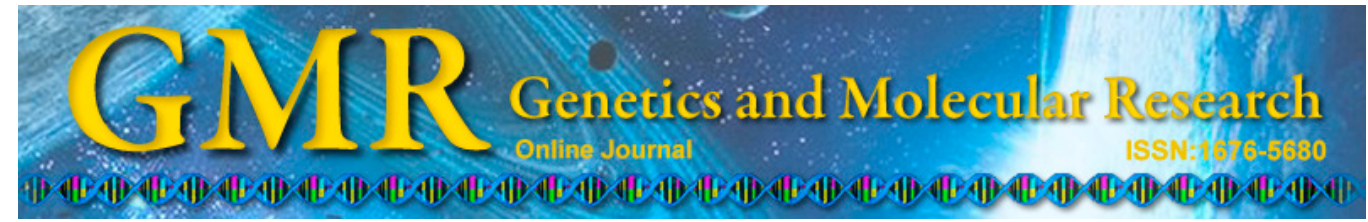

\title{
Genetic diversity analysis of faba bean (Vicia faba L.) germplasms using sodium dodecyl sulfate-polyacrylamide gel electrophoresis
}

\author{
W.W. Hou ${ }^{1 *}$ X.J. Zhang ${ }^{2 *}$, J.B. Shi ${ }^{1}$ and Y.J. Liu ${ }^{1}$ \\ ${ }^{1}$ Qinghai Academy of Agricultural and Forestry Sciences, \\ Qinghai University, Xining, Qinghai, China \\ ${ }^{2}$ College of Eco-Environmental Engineering, \\ Qinghai University, Xining, Qinghai, China \\ *These authors contributed equally to this study. \\ Corresponding author: Y.J. Liu \\ E-mail: 13997058356@163.com
}

Genet. Mol. Res. 14 (4): 13945-13953 (2015)

Received January 29, 2015

Accepted May 25, 2015

Published October 29, 2015

DOI http://dx.doi.org/10.4238/2015.October.29.15

\begin{abstract}
To investigate genetic diversity and relationships of 101 faba bean (Vicia faba L.), landraces and varieties from different provinces of China and abroad were analyzed by sodium dodecyl sulfate (SDS)-polyacrylamide gel electrophoresis (PAGE). A total of 2625 unambiguous and stable bands from 101 germplasms were detected, and 36 different bands were classified according to the electrophoretic mobility patterns of the proteins as determined by the SDS-PAGE analysis, of which 16 were polymorphic. Besides the common bands, the protein bands of $92,75,62,40,34,17$, and $13 \mathrm{kDa}$ presented the highest frequencies of 92.08, 90.10, 99.01, 95.05, 95.05, 98.02, and $95.05 \%$, respectively. The other 29 polymorphic protein bands showed higher polymorphism with 16.09 polymorphic bands in average. The genetic similarity of the 101 genotypes tested varied from 0.6111 to 0.9722 , with an average of 0.7122 . Cluster analysis divided the 101 genotypes into six major clusters, which was consistent with
\end{abstract}


the systematic classification of faba bean done in previous studies. The overall results indicated that SDS-PAGE was a useful tool for genetic diversity analysis and laid a solid foundation for future faba bean breeding.

Key words: Faba bean; Protein; SDS-PAGE; Genetic similarity; Cluster analysis

\section{INTRODUCTION}

Faba bean (Vicia faba L.) is one of the most important cultivated legume crops in the whole world. It is a legume, which is a primary food source for humans, and is popular due to its high seed protein content (Ye et al., 2003). Additionally, faba bean plays an important role in crop rotation, nitrogen fixation (Kaur et al., 2012), disease and weed control (Murray et al., 1988; Schmidtke and Rauber, 2000). Faba bean $(2 n=2 x=12)$ is an autodiploid plant with fewer chromosome numbers than other Vicia species (Raina and Ogihara, 1995), but map-based cloning and marker assistant selection in faba bean have been enormously challenging because of the huge genome size (13,000 Mb) (Bennett et al., 1982; Johnston et al., 1999).

To date, a total of 38,360 faba bean germplasm from different countries have been conserved at the International Center for Agricultural Research in the Dry Areas (ICARDA), Syria (Duc et al., 2010). China is the biggest country with respect to growing area and production of faba bean, especially in the northwest and southwest areas. Various surveys have been conducted to describe the handling and genetic variation of faba bean collections.

Over the past few years, faba bean breeders have succeeded in improving yield, disease and pest resistance, as well as quality and agronomic performance, by using excellent germplasm resources. Genetic diversity is a key factor for crop improvement. However, due to the frequent utilization of a few elite germplasm lines, genetic diversity in faba bean is often decreased. Previous studies have made remarkable progress in analyzing genetic diversity of faba bean, especially with various DNA molecular markers. Random-amplified polymorphic DNA markers were first used to test relationships between three faba bean inbred lines obtained from Europe and the Mediterranean region (Link et al., 1995). Molecular variation among winter (Zong et al., 2009) and spring (Zong et al., 2010) faba bean ecotypes have been examined using amplified fragments length polymorphism markers. Inter-simple sequence repeat markers were used to analyze the genetic diversity and relationship of global faba bean germplasm (Terzopoulos and Bebeli, 2008; Wang et al., 2012).

The degree of genetic diversity can reflect the level of genetic progress in future breeding. Therefore, evaluation of faba bean genetic diversity will be helpful for breeding programs. Previous studies have indicated that the electrophoretic pattern of seed proteins can be utilized as a reliable tool to clarify specific phylogenetic relationships among species (Potokina et al., 2003). However, only few reports about protein genetic diversity of faba bean have been published; Eckert and Barrett (1993) studied clonal reproduction and patterns of genotypic diversity. Therefore, the study of genetic diversity of faba bean with sodium dodecyl sulfate (SDS)-polyacrylamide gel electrophoresis (PAGE) is important. To the best of our knowledge, this is the first application of SDS-PAGE analysis for the assessment of genetic diversity among faba bean collections. 
In order to measure the genetic diversity of faba bean with SDS-PAGE, we compared the genetic relationship of faba bean germplasm, and we have provided a basis for understanding the genetic diversity of faba bean. Moreover, we have also put forward suggestions for the further improvement of faba bean.

\section{MATERIAL AND METHODS}

\section{Plant materials}

A total of 101 faba bean accessions, including 74 varieties from different provinces of China and 27 accessions from abroad (Table S1) were selected from the China National GenBank, located at the Institute of Crop Science (ICS), Chinese Academy of Agricultural Sciences (CAAS), Beijing. All the representative samples of faba bean were grown on the experimental farm of Qinghai Agriculture and Forestry Academy. In this study, a representative collection of 74 elite faba bean accessions from the major faba bean-producing regions of China, and 27 germplasms from the rest of the world, were analyzed using SDS-PAGE analysis. The two main varieties in China, the spring and winter faba bean, were selected for this study to compare the different ecotypes of faba bean germplasm.

\section{Sample preparation and electrophoresis}

Total protein was extracted from bulk-crushed seeds as described by Chen (1995). Dry powder $(0.05 \mathrm{~g})$ was soaked in $0.4 \mathrm{~mL}$ water for at least $24 \mathrm{~h}$, and then the mixture was placed in an Eppendorf centrifuge for $30 \mathrm{~min}$ at $8000 \mathrm{~g}$. The supernatant was preserved at $4{ }^{\circ} \mathrm{C}$ for sample preparation. Each sample was suspended in a medium containing $2 \%$ SDS (w/v), $5 \%$ 2-mercaptoethanol (w/v), 0.001\% pyronin (w/v), 10\% glycerol $(\mathrm{v} / \mathrm{v})$, and $1 \mathrm{M}$ Tris- $\mathrm{HCl}$, $\mathrm{pH}$ 6.8. The samples were left for $3 \mathrm{~h}$ at room temperature and shaken every $15 \mathrm{~min}$. Then, the mixture was placed in a boiling water bath for $3-5$ min and cooled at $4^{\circ} \mathrm{C}$.

SDS-PAGE was performed on $4 \%$ slab gels in a discontinuous buffer system as described by Laemmli (1970). A constant electric current of $30 \mathrm{~mA}$ was used to run two gels for $10 \mathrm{~h}$.

\section{Statistical analysis}

SDS-PAGE analysis was performed in duplicate, and only those bands obtained clearly twice were scored either 1 (present), or 0 (absent). The average diversity index among accessions and geographical groups was measured according to Shannon-Weaver. Data generated from SDS-PAGE analysis were analyzed with Jaccard similarity coefficient (Jaccard, 1908).

The cluster analysis of different geographical groups was carried out using unweighted pair-group method with arithmetic average (UPGMA), employing SAHN (sequential, agglomerative, hierarchical, and nested clustering) from the NTSYSpc (version 2.10) (Rohlf, 2005). The dendrogram was drawn by MEGA3.1.

\section{RESULTS AND DISCUSSION}

The SDS-PAGE analysis showed 2625 unambiguous and stable bands from 101 germplasms (Table 1). Each variety produced different numbers of bands; the numbers 
of protein bands ranged from 21 to 31 (Table 2). Based on the electrophoretic mobility of proteins, 36 different bands were present (Figure 1), of which 16 were polymorphic, with an average ratio of $44.69 \%$ polymorphic fragments per variety. Percentage of polymorphic bands ranged from $58.33 \%$ to a minimum of $30.56 \%$ with an average of $93 \%$.

\begin{tabular}{|c|c|c|c|c|c|c|c|}
\hline No. & $\begin{array}{l}\text { Total } \\
\text { bands }\end{array}$ & $\begin{array}{l}\text { Polymorphic } \\
\text { bands }\end{array}$ & $\begin{array}{l}\text { Polymorphism } \\
\text { percentage (\%) }\end{array}$ & No. & $\begin{array}{l}\text { Total } \\
\text { bands }\end{array}$ & $\begin{array}{l}\text { Polymorphic } \\
\text { bands }\end{array}$ & $\begin{array}{l}\text { Polymorphism } \\
\text { percentage (\%) }\end{array}$ \\
\hline 1 & 29 & 19 & 52.78 & 52 & 27 & 17 & 47.22 \\
\hline 2 & 26 & 16 & 44.44 & 53 & 24 & 14 & 38.89 \\
\hline 3 & 24 & 14 & 38.89 & 54 & 26 & 16 & 44.44 \\
\hline 4 & 24 & 14 & 38.89 & 55 & 23 & 23 & 63.89 \\
\hline 5 & 25 & 15 & 41.67 & 56 & 21 & 11 & 30.56 \\
\hline 6 & 25 & 15 & 41.67 & 57 & 28 & 18 & 50.00 \\
\hline 7 & 26 & 16 & 44.44 & 58 & 23 & 13 & 36.11 \\
\hline 8 & 26 & 16 & 44.44 & 59 & 25 & 15 & 41.67 \\
\hline 9 & 29 & 19 & 52.78 & 60 & 24 & 14 & 38.89 \\
\hline 10 & 23 & 13 & 36.11 & 61 & 26 & 16 & 44.44 \\
\hline 11 & 26 & 16 & 44.44 & 62 & 29 & 19 & 52.78 \\
\hline 12 & 22 & 12 & 33.33 & 63 & 24 & 14 & 38.89 \\
\hline 13 & 28 & 18 & 50.00 & 64 & 28 & 18 & 50.00 \\
\hline 14 & 28 & 18 & 50.00 & 65 & 27 & 17 & 47.22 \\
\hline 15 & 27 & 17 & 47.22 & 66 & 24 & 14 & 38.89 \\
\hline 16 & 26 & 16 & 44.44 & 67 & 25 & 15 & 41.67 \\
\hline 17 & 22 & 12 & 33.33 & 68 & 27 & 17 & 47.22 \\
\hline 18 & 25 & 15 & 41.67 & 69 & 24 & 14 & 38.89 \\
\hline 19 & 27 & 17 & 47.22 & 70 & 26 & 16 & 44.44 \\
\hline 20 & 26 & 16 & 44.44 & 71 & 25 & 15 & 41.67 \\
\hline 21 & 27 & 17 & 47.22 & 72 & 28 & 18 & 50.00 \\
\hline 22 & 28 & 18 & 50.00 & 73 & 25 & 15 & 41.67 \\
\hline 23 & 25 & 15 & 41.67 & 74 & 23 & 13 & 36.11 \\
\hline 24 & 27 & 17 & 47.22 & 75 & 24 & 14 & 38.89 \\
\hline 25 & 27 & 17 & 47.22 & 76 & 25 & 15 & 41.67 \\
\hline 26 & 28 & 18 & 50.00 & 77 & 25 & 15 & 41.67 \\
\hline 27 & 26 & 16 & 44.44 & 78 & 27 & 17 & 47.22 \\
\hline 28 & 26 & 16 & 44.44 & 79 & 26 & 16 & 44.44 \\
\hline 29 & 25 & 15 & 41.67 & 80 & 23 & 13 & 36.11 \\
\hline 30 & 25 & 15 & 41.67 & 81 & 27 & 17 & 47.22 \\
\hline 31 & 24 & 14 & 38.89 & 82 & 24 & 14 & 38.89 \\
\hline 32 & 28 & 18 & 50.00 & 83 & 25 & 15 & 41.67 \\
\hline 33 & 25 & 15 & 41.67 & 84 & 29 & 19 & 52.78 \\
\hline 34 & 26 & 16 & 44.44 & 85 & 27 & 17 & 47.22 \\
\hline 35 & 25 & 15 & 41.67 & 86 & 25 & 15 & 41.67 \\
\hline 36 & 26 & 16 & 44.44 & 87 & 27 & 17 & 47.22 \\
\hline 37 & 29 & 19 & 52.78 & 88 & 27 & 17 & 47.22 \\
\hline 38 & 26 & 16 & 44.44 & 89 & 26 & 16 & 44.44 \\
\hline 39 & 28 & 18 & 50.00 & 90 & 22 & 12 & 33.33 \\
\hline 40 & 27 & 17 & 47.22 & 91 & 27 & 17 & 47.22 \\
\hline 41 & 25 & 15 & 41.67 & 92 & 27 & 17 & 47.22 \\
\hline 42 & 27 & 17 & 47.22 & 93 & 27 & 17 & 47.22 \\
\hline 43 & 28 & 18 & 50.00 & 94 & 26 & 16 & 44.44 \\
\hline 44 & 27 & 17 & 47.22 & 95 & 26 & 16 & 44.44 \\
\hline 45 & 28 & 18 & 50.00 & 96 & 26 & 16 & 44.44 \\
\hline 46 & 28 & 18 & 50.00 & 97 & 27 & 17 & 47.22 \\
\hline 47 & 28 & 18 & 50.00 & 98 & 28 & 18 & 50.00 \\
\hline 48 & 25 & 15 & 41.67 & 99 & 29 & 19 & 52.78 \\
\hline 49 & 27 & 17 & 47.22 & 100 & 24 & 14 & 38.89 \\
\hline 50 & 25 & 15 & 41.67 & 101 & 31 & 21 & 58.33 \\
\hline 51 & 26 & 16 & 44.44 & & & & \\
\hline
\end{tabular}


Table 2. Distribution frequency of protein bands in 101 faba bean genotypes.

\begin{tabular}{lcc}
\hline Total bands & Accession No. & Frequency (\%) \\
\hline 31 & 1 & 0.99 \\
29 & 6 & 5.94 \\
28 & 14 & 13.86 \\
27 & 21 & 20.79 \\
26 & 20 & 19.80 \\
25 & 19 & 18.81 \\
24 & 11 & 10.89 \\
23 & 5 & 4.95 \\
22 & 3 & 2.97 \\
21 & 1 & 0.99 \\
\hline
\end{tabular}

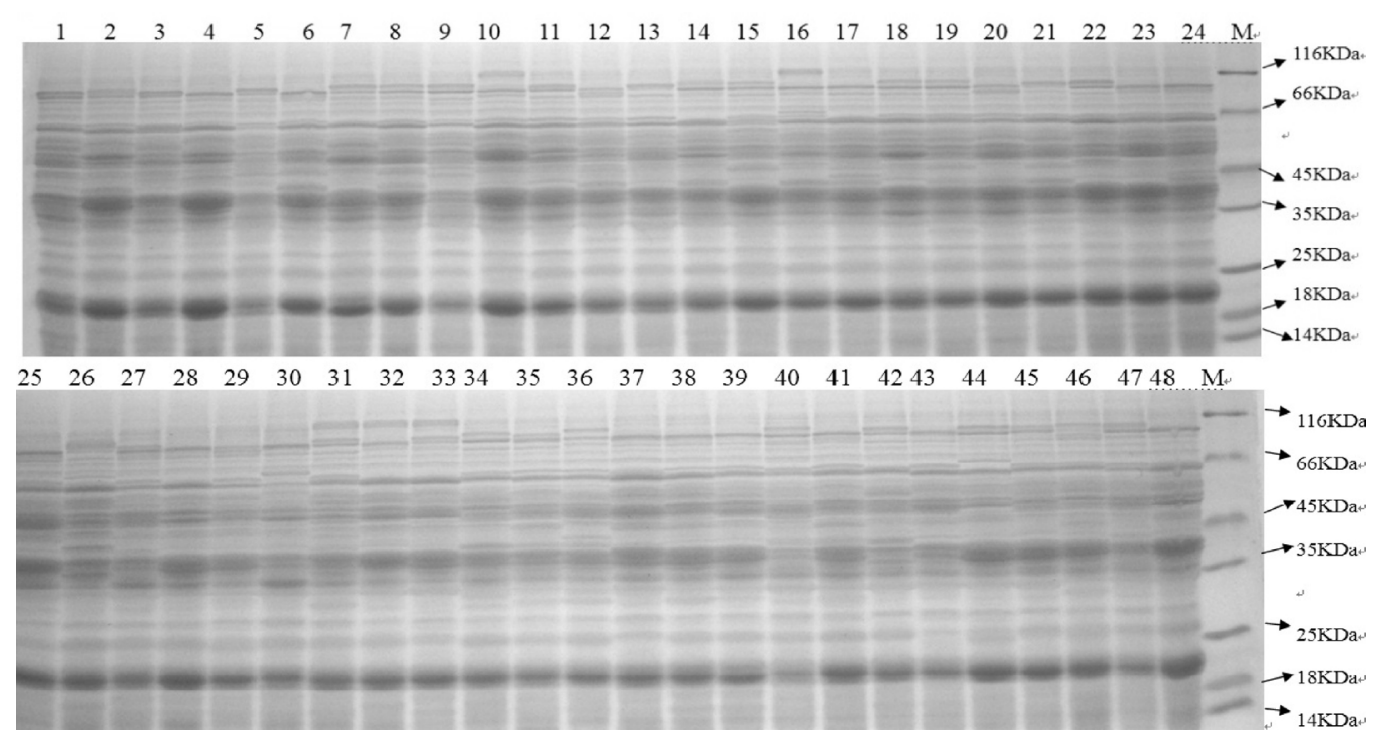

Figure 1. Representative SDS-PAGE amplification pattern generated in part of 101 faba bean samples. Lanes 1 to 48 = partial faba bean germplasms; lane $M=100-\mathrm{kDa}$ marker.

SDS-PAGE analysis indicated that 10 protein molecular masses, viz. 68, 42, 35, 29, $26,22,21,20,16$, and $14 \mathrm{kDa}$ were common bands for all the varieties tested, and 92, 75, $62,40,34,17$, and $13 \mathrm{kDa}$ were detected in some varieties with high frequency. The genetic similarities of different germplasms were calculated with the genetic similarity method. Genetic similarity index of different geographical groups of germplasm ranged from 0.6111 to 0.9722 with an average of 0.7122 . The collections from Northwest of China showed the highest genetic diversity, while the faba bean germplasm from central China showed the lowest level of diversity. The similarity matrix correlation analysis indicated a low level of genetic diversity among varieties, viz. HUAN3, 324, BEIYUAN, XIAOHUDOU, CHENDOU, and ZAOCAN. The NEW1, SPANNIA299, and ENGLAND38 had similar genetic diversity parameters, which indicated that those groups had higher diversity.

Clustering analysis of faba beans belonging to different Chinese provinces and accessions obtained from other countries was carried out by POPGEN1.32 (Yeh and Boyle, 1997) based on the UPGMA method, and the dendrogram was drawn by the MEGA3.1 
software (Tamura et al., 2007). The results showed that 101 faba bean accessions were divided into six major groups (Figure 2).

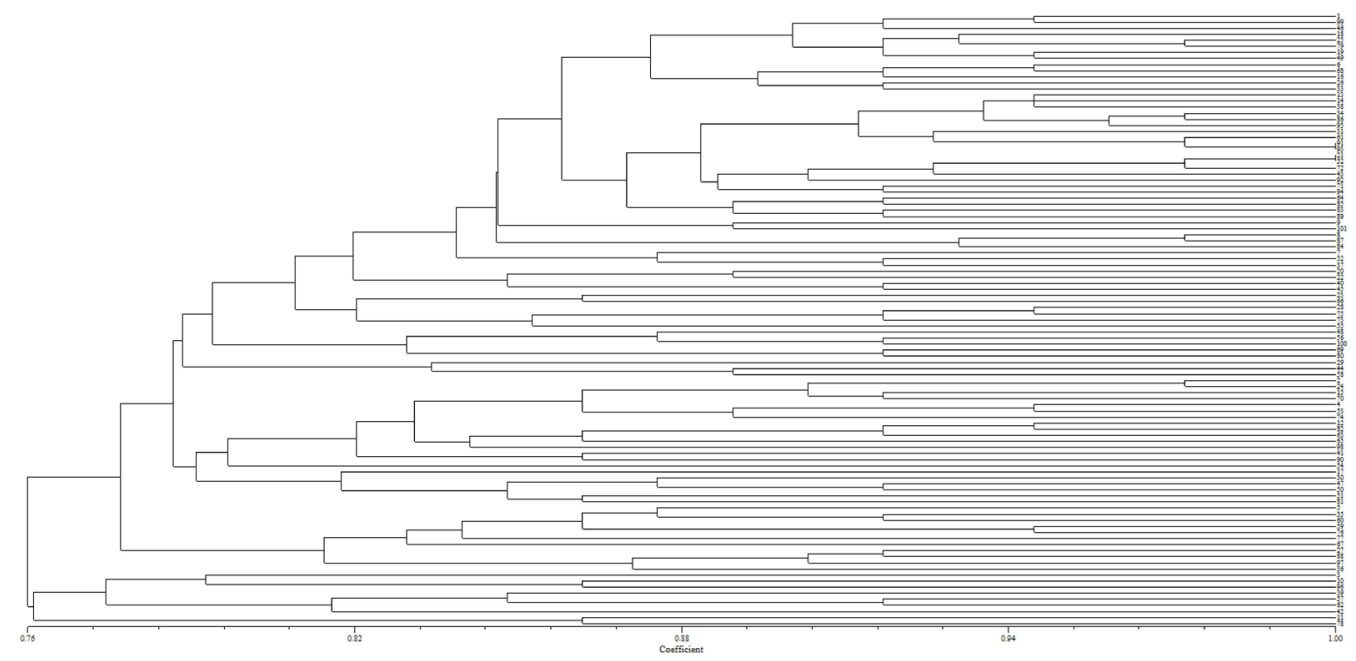

Figure 2. UPGMA dendrogram of 101 faba bean germplasms from different provinces in China and rest of the world.

The first group (group I) included 77 faba bean accessions, with a percentage of $76.23 \%$ among the 101 varieties tested, and the genetic similarity index of 77 different germplasm ranged from 0.6389 to 0.9722 . Group I showed the highest polymorphism, which included 36 bands, and contained three subgroups. The second group (group II) comprised five faba bean accessions with a percentage of $4.95 \%$. The diversity and genetic similarity index of group II were 3.6323 , and 0.7778 to 0.8889 , respectively. Two collections, viz. WUSHAN and 1638 in group II, showed a high level of genetic diversity, which indicated that they had a closer genetic relationship. This group generated 32 different bands, of which 18 bands were common, with a percentage of $56.25 \%$. SDS-PAGE analysis showed that all faba bean genotypes in group II produced the specific band of $46 \mathrm{kDa}$, which can be used as a diagnostic characteristic. The third group (group III) consisted of one faba bean germplasm 0908 from Gansu Province in Northwest of China. Germplasm 0908 generated 25 types of bands, and produced the expected bands of 116 and $66 \mathrm{kDa}$. The fourth group (group IV) had three faba bean collections with a percentage of $3.96 \%$. The diversity and genetic similarity index of group were 3.1826 , and 0.7778 to 0.8611 , respectively. Thirty-two bands were observed in group IV, and 22 of them were common bands. Compared with other groups, group IV had four specific bands of $66,60,55,50$, and $45 \mathrm{kDa}$. The fifth group contained 6 germplasms of the faba bean collections tested. The diversity and genetic similarity index of group V were 3.0753 , and 0.8056 to 0.9167 , respectively. Group V included 31 different bands, and 19 of these were common bands. The 6 germplasms in group $\mathrm{V}$ produced the band of $87 \mathrm{kDa}$, but lacked the bands of 81 and $46 \mathrm{kDa}$. The remaining 9 faba bean collections belonged to the sixth group. The genetic similarity index of group VI was 0.8333 to 0.9167 . These 9 varieties 
did not contain the bands of 116 and $81 \mathrm{kDa}$. The UPGMA clustering analysis indicated that there was a high level of protein diversity among different faba bean collections.

Group analysis of the genotypes according to their geographic origin showed that the landraces from Qinghai Province grouped together, other faba bean germplasms from different provinces of China formed another group, while the remaining faba bean collections from the rest of the world grouped together.

Based on SDS-PAGE analysis of 101 faba bean germplasms, genetic diversity between the three geographic groups was calculated (Table 3). Genotypes from Qinghai Province showed the highest genetic index among the three groups. The average genetic diversity of 101 faba bean germplasms was 5.1884, and the genetic diversity index between different groups was 0.0121 , while the genetic diversity index in the group was 0.9879 . These results indicated that the diversity of faba bean protein depended on the same group rather than different groups.

\begin{tabular}{lc} 
Table 3. Genetic index of three geographical groups. \\
\hline Geographical group & Genetic index \\
\hline Genotypes from Qinghai & 5.3097 \\
Genotypes from China & 5.0703 \\
Genotypes from abroad & 4.9967 \\
Average genetic diversity index & 5.1255 \\
Total average genetic diversity index & 5.1884 \\
Genetic diversity index within group & 0.9879 \\
Genetic diversity index between group & 0.0121 \\
\hline
\end{tabular}

The assessment of the genetic variation within SDS-PAGE is important for the effective conservation and utilization of genetic resources in breeding programs, and it could be dramatically enhanced by using molecular genotyping tools. Genetic variability in faba bean has been previously studied using different DNA molecular markers (Link et al., 1995; Terzopoulos and Bebeli, 2008; Zong et al., 2009, 2010; Wang et al., 2012). However, this is the first time that SDS-PAGE analysis has been utilized for estimating genetic diversity in faba bean. In this study, the genetic diversity of 101 accessions of different faba bean ecotypes from regions in China and the rest of the world was analyzed by SDS-PAGE.

In the current study, we identified that SDS-PAGE was a powerful technique for the assessment of genetic variability because it has shown a high degree of reproducibility and discriminatory power, as well as a high polymorphism rate in many previous genetic studies with molecular markers. In this study, SDS-PAGE analysis produced 2625 unambiguous and stable bands from 101 germplasms, and 36 different bands were classified based on electrophoretic mobility of proteins, of which 16 were polymorphic, with an average ratio of $44.69 \%$ polymorphic fragments per variety. Each variety produced different numbers of bands, the numbers of protein bands ranged from 21 to 31 . All SDS-PAGE generated 100\% polymorphic fragments, so the number of fragments and the polymorphism percentages in this study were higher than those obtained in other genetic diversity studies of faba bean using different molecular markers. The variation of polymorphism rate reflects the extent of genetic divergence among and within the populations and/or genotypes studied, and SDSPAGE combinations used. These findings demonstrate the usefulness of SDS-PAGE analysis in detecting genetic variability in various plant species. 
The genetic similarity of the genotypes tested varied from 0.6111 to 0.9722 , with an average of 0.7122 . The genetic diversity index within group was much higher than that between groups, which indicated that the main variation of protein occurred within populations. Cluster analysis divided the accessions into six major clusters, which was consistent with previous genetic diversity studies of faba beans.

In conclusion, our SDS-PAGE analysis results suggest that the 101 faba bean collections utilized, are genetically diverse, which is consistent with previous studies. The clustering results of the protein genetic diversity of faba bean were largely dependent on growth habit, geographical origin, and ecological distribution. However, a broader investigation of morphological and agronomical characteristics is required to confirm the distinct differentiation of gene pools between China and the rest of the world.

\section{Conflicts of interest}

The authors declare no conflict of interest.

\section{ACKNOWLEDGMENTS}

Research supported by the China Agriculture Research System (CARS-09) and the “973” Project from the Ministry of Science and Technology of China (\#2010CB134408).

\section{Supplementary material}

\section{REFERENCES}

Bennett MD, Smith JB and Heslop-Harrison JS (1982). Nuclear DNA amounts in angiosperms. Proc. R. Soc. Lond. B Biol. Sci. 216: 179-199.

Chen Y (1995). Research on biochemistry. China Agriculture Press, Beijing, 23-34.

Duc G, Bao SY, Baum M, Redden B, et al. (2010). Diversity maintenance and use of Vicia faba L. genetic resources. Field Crops Res. 115: 270-278.

Eckert CG and Barrett SC (1993). Clonal reproduction and patterns of genotypic diversity in Decodon verticillatus (Lythraceae). Am. J. Bot. 80: 1175-1182.

Jaccard P (1908). Nouvelles recherches sur la distribution florale. Bull. Soc. Vaud. Sci. Nat. 44: 223-270.

Johnston JS, Bennett MD, Rayburn AL, Galbraith DW, et al. (1999). Reference standards for determination of DNA content of plant nuclei. Am. J. Bot. 86: 609-613.

Kaur S, Pembleton LW, Cogan NO, Savin KW, et al. (2012). Transcriptome sequencing of field pea and faba bean for discovery and validation of SSR genetic markers. BMC Genomics 13: 104.

Laemmli UK (1970). Cleavage of structural proteins during the assembly of the head of bacteriophage T4. Nature 227: 680-685.

Link W, Dixkens C, Singh M, Schwall M, et al. (1995). Genetic diversity in European and Mediterranean faba bean germplasm revealed by RAPD markers. Theor. Appl. Genet. 90: 27-32.

Murray GA, Wser D, Gusta LV and Steve G (1988). World crops: Cool season food legumes (Summerfield RJ, ed.). Kluwer, London, 831-843.

Potokina E, EndoY, Eggi E and Ohashi H (2003). Electrophoretic patterns of seed proteins in the East Asian Vicia species (Leguminosae) and their systematic utility. J. Jap. Bot. 78: 29-37.

Raina SN and Ogihara Y (1995). Ribosomal DNA repeat unit polymorphism in 49 Vicia species. Theor. Appl. Genet. 90 : 477-486.

Rohlf FJ (2005). Ntsys-pc, Numerical Taxonomy and Multivariate Analysis System. Version 2.2. Exeter Publishing Ltd., New York.

Schmidtke K and Rauber R (2000). Grain legumes and nitrogen cycling in organic crop systems. Grain Legumes 30: 16-17. 
Tamura K, Dudley J, Nei M and Kumar S (2007). MEGA4: molecular evolutionary genetics analysis (MEGA) software version 4.0. Mol. Biol. Evol. 24: 1596-1599.

Terzopoulos PJ and Bebeli PJ (2008). Genetic diversity analysis of Mediterranean faba bean (Vicia faba L.) with ISSR markers. Field Crops Res. 108: 39-44.

Wang H, Zong X, Guan J, Yang T, et al. (2012). Genetic diversity and relationship of global faba bean (Vicia faba L.) germplasm revealed by ISSR markers. Theor. Appl. Genet. 124: 789-797.

Ye Y, Lang L, Xia M and Tu J (2003). Faba beans in China (in Chinese). China Agriculture Press, Beijing, 1-15.

Yeh FC and Boyle TJ (1997). Population genetic analysis of co-dominant and dominant markers and quantitative traits. Belg. J. Bot. 129: 157.

Zong X, Liu X, Guan J, Wang S, et al. (2009). Molecular variation among Chinese and global winter faba bean germplasm. Theor. Appl. Genet. 118: 971-978.

Zong X, Ren J, Guan J, Wang S, et al. (2010). Molecular variation among Chinese and global germplasm in spring faba bean areas. Plant Breed. 129: 508-513. 